\title{
Almir de Andrade y Raúl Scalabrini Ortiz: dos intelectuales del populismo clásico
}

\section{Almir de Andrade and Raúl Scalabrini Ortiz: Two Intellectuals from the Realm of Classical Populism}

\author{
Rafael Rojas \\ El Colegio de México, México \\ Centro de Estudios Históricos \\ rerojas@colmex.mx
}

Resumen: Este artículo propone una reconstrucción de las ideas centrales de dos intelectuales latinoamericanos, el brasileño Almir de Andrade y el argentino Raúl Scalabrini Ortiz, durante el periodo de formación de los populismos varguista y peronista a mediados del siglo xx. Interesa, en esta reconstrucción, la manera en que aquellos intelectuales y las publicaciones que ellos impulsaron, como la revista Cultura Política y Cuadernos de FORJA, asumían los dilemas de la nación y las relaciones internacionales, la sociedad y su diversidad racial y cultural, el Estado y su papel en el desarrollo económico y la extensión de los derechos sociales. Este recorrido permite replantear viejas cuestiones de la historia intelectual y política latinoamericana como el rol de la ideología en el populismo clásico, la intervención de los intelectuales en la esfera pública y el campo referencial de las ciencias sociales que se involucra en los discursos de legitimación política.

cómo citAR: Almir de Andrade y Raúl Scalabrini Ortiz: dos intelectuales del populismo clásico. Secuencia (109), e1805. DOI: https://doi.org/10.18234/secuencia.v0i109.1805

c) Esta obra está protegida bajo una Licencia Creative Commons Atribución-NoComercial 4.0 Internacional. 
Palabras clave: intelectuales; populismo; ideología; ciencias sociales; nación; nacionalismo; imperialismo; soberanía; justicia social.

Abstract: This article proposes a reconstruction of the central ideas of two Latin American intellectuals, the Brazilian Almir de Andrade and the Argentine Raúl Scalabrini Ortiz, during the period of formation of the Varguista and Peronist populisms in the mid-20th century. Of interest in this reconstruction is the way these intellectuals and the publications they promoted, such as the journal Cultura Politica and Cuadernos de FORJA, assumed the dilemmas of the nation and international relations, society and its racial and cultural diversity, the state and its role in economic development and the extension of social rights. This journey allows one to revisit old issues in Latin American intellectual and political history, such as the role of ideology in classical populism, the intervention of intellectuals in the public sphere and the referential field of the social sciences involved in the discourses of political legitimation.

Keywords: intellectuals; populism; ideology; social sciences; nation; nationalism; imperialism; sovereignty; social justice.

Recibido: 16 de diciembre de 2019 Aceptado: 24 de marzo de 2020 Publicado: 2 de marzo de 2021

$E^{n}$ n un estudio comparado sobre los populismos varguista y peronista, Alejandro Groppo, discípulo del neomarxista Ernesto Laclau, sostiene que aunque tanto en Brasil como en Argentina se produjo una apropiación del concepto de Revolución, en el caso de Getulio Vargas y el Estado Novo brasileño, aquella combinatoria simbólica, que entrelazaba elementos de golpe militar, reforma gubernamental y movilización de masas, resultó menos desestabilizadora para la oligarquía nacional que el experimento de Juan Domingo Perón en Argentina. Afirma Groppo que antes de la llamada "Revolución del 30", Vargas, como ministro de Hacienda de Washington Luis o como gobernador de Río Grande do Sul, era percibido como un actor menos disruptivo que Perón como ministro de Trabajo y Previsión Social, luego de la también llamada "Revolución argentina de 1943" (Groppo, 2009, pp. 291-303). Vargas, a diferencia de Perón, se estableció desde un inicio como un "significante de 
consenso", llamado a asegurar una "estabilización del régimen republicano" luego del colapso del modelo oligárquico del primer cuarto de siglo (Groppo, 2009, p. 305).

Si bien esa tesis es perfectamente sostenible desde la historia política comparada, una aproximación al paralelo desde la historia intelectual permite afinar más las diferencias en la incorporación del concepto revolucionario a ambos proyectos populistas, así como advertir las semejanzas en el proceso de polarización política que se vive en ambos países a mediados del siglo xx. Leyendo a los ideólogos de Vargas y Perón y algunas intervenciones estratégicas de ambos líderes en la construcción del nuevo glosario de la política nacional en Suramérica, comprendemos mejor la forma en que el populismo clásico se relacionó con la tradición revolucionaria latinoamericana, que comenzó en México en 1910, y que seguirían el aprismo peruano y los nacionalismos revolucionarios de Centro América y el Caribe desde los años veinte.

Interesa, aquí, releer a ideólogos del varguismo y el peronismo, en el campo intelectual brasileño y argentino de mediados del siglo $\mathrm{xx}$, con el fin de elucidar las formas de representación del pueblo o las masas que pusieron a circular a ambos Estados y los discursos de la identidad nacional que transmitían. Se trata de ideólogos que no tuvieron, necesariamente, un vínculo de "intelectuales orgánicos" con sus respectivos Estados, especialmente en el caso argentino, pero contribuyeron a visibilizar el papel que aquellos proyectos asignaban a Brasil y Argentina en las Américas y el mundo. A través de los escritos de dos intelectuales, el brasileño Almir de Andrade y el argentino Raúl Scalabrini Ortiz, y de revistas por ellos impulsadas como Cultura Política y Cuadernos de FORJA, observaremos que el nacionalismo brasileño adoptaba una estructura argumental sociológica, abierta a la interlocución con las grandes potencias atlánticas, mientras que el nacionalismo argentino combinaba acentos criollistas e hispanoamericanistas, puestos en función de una resistencia regional a la hegemonía de Gran Bretaña y Estados Unidos en el hemisferio. ${ }^{1}$

El papel de la ideología en los populismos clásicos ha llamado la atención de historiadores y politólogos. Desde los estudios tempranos de Gino Germani, Torcuato S. di Tella y Octavio Ianni se estableció el lugar común de que el populismo, a diferencia de los socialismos, carecía de ideología u

1 Aunque escasa, hay una bibliografía atendible sobre aquellos dos grupos intelectuales: Bergel (2018); Fiorucci (2011); Lippi Oliveira, Pimenta y Castro Gomez (1982); Mio Salla (2017); Sigal (1991); Silva de Paiva (2009); Velloso (2003). 
operaba con doctrinas de régimen reducibles a discursos superficiales de legitimación (Germani, di Tella e Ianni, 1973, p. 2; Ianni, 1975, pp. 52-55). El propio Ernesto Laclau, aunque evolucionó en su percepción del populismo desde la izquierda marxista en los años setenta a la perspectiva neomarxista de los años 2000, preservó, a través de la noción de "significante vacío", una idea débil del papel de la ideología en el populismo (Laclau, 1978, pp. 230-232, y 2005, pp. 129-131). La historia intelectual de los populismos de mediados del siglo xx en América Latina permite cuestionar esa visión de "ideología delgada", que han reiterado otros autores, como Cas Mudde y Ben Stanley, y que subestima el peso de las teorías sociales positivistas, funcionalistas y estructuralistas en aquellos movimientos (Mudde, 2004, pp. 541-563; Stanley, 2008, pp. 95-110).

Este ensayo se propone replantear el problema de la construcción de ideologías de Estado o doctrinas de régimen bajo modelos políticos del populismo "clásico" o "moderno" (Finchelstein, 2018, pp. 126-141). Entendemos por estos, estrictamente, los proyectos varguista y peronista en Brasil y Argentina, respectivamente, antes de la guerra fría, $y$, aunque no desconocemos experiencias similares en el gobierno o la oposición en otros países latinoamericanos, como podría ser el caso del APRA peruano, suscribimos la distinción entre aquellos regímenes y el cardenismo mexicano, más claramente inscrito en la tradición del nacionalismo revolucionario (Knight, 1998, pp. 223-248). Algo que llama la atención, sin embargo, es que si bien se trata de tradiciones distintas dentro de la izquierda latinoamericana, también en el populismo suramericano se produce una apropiación del concepto de Revolución que da sentido a la práctica intelectual y el debate ideológico.

\section{ALMIR DE ANDRADE Y EL TODO ORGÁNICO}

Entre los múltiples intelectuales adscritos con mayor o menor profundidad en los primeros gobiernos de Getulio Vargas, en los años treinta del siglo xx, y al lanzamiento del Estado Novo en los años cuarenta, destaca el abogado, sociólogo y economista Almir Bonfim de Andrade (1911-1991). Este escritor estudió derecho en la Universidad de Río de Janeiro y, a principios de los años treinta, estuvo ligado a los círculos "integralistas" o filofascistas de publicaciones como el Jornal do Brasil y, sobre todo, A Razão de São Paulo, dirigido por Plinio Salgado, futuro jefe de la Acción Integralista Brasileira (АІB), principal 
asociación del fascismo suramericano. Como observa Helio Trindade, en su clásico estudio sobre el "integralismo", en los años veinte y treinta, la crisis del liberalismo y, específicamente, de la vieja república brasileña, produjo una aproximación al fascismo de actores intelectuales y políticos que no provenían de la derecha católica nacionalista sino de una izquierda vanguardista y liberal, desencantada con el republicanismo oligárquico (Trindade, 1974, pp. 106-110 y 172-188).

Para fines de la década de los treinta, Andrade era profesor de la Facultad de Derecho en Río y colaboraba con los planes de capacitación de maestros del Ministerio de Educación varguista, ya entonces encabezado por Gustavo Capamena. Fue ahí que entró en contacto con la psicología social de André Omdrebane, profesor de la Sorbona, invitado a Brasil a fines de los treinta. A través de Capamena y del ministro de Justicia, Francisco Luís da Silva Campos, Andrade se relacionó con el director del Departamento de Imprenta y Propaganda (DIP) del Estado Novo, Lourival Fontes, quien le ofreció la dirección de la revista Cultura Política, principal plataforma ideológica del varguismo. Por medio de una política editorial cuidadosa y, a la vez, comprometida, Andrade atrajo hacia aquella revista a figuras de gran prestigio intelectual, como Gilberto Freyre, Graciliano Ramos y Nelson Werneck Sodré, que originalmente habían estado distanciados u opuestos al varguismo. En 1943, gracias a su desempeño al frente de Cultura Política, Andrade pasó a ser director de la Agencia Nacional de publicidad del Estado Novo.

Es interesante rastrear la aproximación intelectual de Andrade al varguismo desde su temprano estudio A verdade contra Freud (1933), escrito con sólo 22 años. El punto de partida de aquel ensayo era una reacción contra una línea del pensamiento occidental que en el primer cuarto del siglo xx había puesto en tela de juicio la tradición filosófica moderna. Andrade mencionaba a Friedrich Nietzsche como precursor de esa escuela intelectual dentro de la que incluía a Henri Bergson y a Sigmund Freud. En todos ellos, un comprensible distanciamiento del positivismo había conducido a un irracionalismo que, a juicio del joven intelectual brasileño, era inconveniente (Andrade, 1933, pp. 19-59). Los primeros libros de Bergson, Essai sur le données inmédiates de la conscience (1889) y Matèrie et mémoire (1896), tenían ese impulso espiritual contra el positivismo más organicista, con el que Andrade simpatizaba. Pero ya el tránsito a las tesis "vitalistas" de L'Énergie spirituelle (1919) implicaba un "experimentalismo científico", que tanto en Bergson como en Freud, era cuestionable (Andrade, 1933, pp. 425-426). 
Andrade mantenía en su libro un tono reposado que no prescindía del reconocimiento del valor intelectual de las teorías de Freud y el movimiento psicoanalítico. Las investigaciones del vienés sobre la histeria y la neurosis, sus ejercicios de interpretación de los sueños, sus ensayos sobre la historia cultural y hasta su teoría del "complejo de Edipo" eran renovaciones del campo de los estudios psicológicos. El movimiento psicoanalítico de la primera generación vienesa (Breuer, Reitler, Adler, Stekel...) había hecho aportes indudables a la clínica y las terapias de la psiquiatría (Andrade, 1933, pp. 73-130). Pero en toda la obra de Freud y sus seguidores, según Andrade, había un "error inicial", de trasfondo filosófico, que respondía a un espíritu de época, propio de todo el pensamiento posthegeliano, para el que la relación dialéctica entre el ser y la conciencia debía ponerse en tela de juicio (Andrade, 1933, pp. 194-214).

Aquel desacuerdo llevaba a Andrade a conclusiones exageradas sobre "la demolición del sistema" psicoanalítico y el "fracaso del genio" de Freud (Andrade, 1933, p. 380). La insistencia del brasileño en que las alienaciones mentales también se formaban en la conciencia denotaba un racionalismo tradicional, muy afín a la herencia positivista. A su vez, las aseveraciones de Andrade sobre la "moral del psicoanálisis" como una "moral del desánimo, el desespero y del suicidio", convergía en la reacción católica o marxista al psicoanálisis. La recepción entusiasta de Freud en los medios de las vanguardias europeas y americanas de los años veinta y treinta, especialmente en el dadaísmo, el futurismo, el surrealismo y el cubismo, colocaba a Andrade en una posición atrasada, cuando no reaccionaria, en relación con el irreverente movimiento literario y artístico brasileño.

En un libro posterior, Aspetos da cultura brasileira (1939), poco antes de encabezar el proyecto de la revista Cultura política, Andrade extendía aquella crítica al psicoanálisis y las vanguardias por medio de una visión integradora de la sociedad y el Estado brasileños. La postura vanguardista arrastraba una defensa de la irracionalidad y el nihilismo que, a juicio de los ideólogos del populismo clásico, no propiciaba el compromiso cívico que demandaba de la ciudadanía el cambio político. Andrade lo sugería al reiterar sus objeciones a Freud, aunque remarcando su perspectiva de "materialismo vulgar" (Andrade, 1939, p. 148). En el médico austriaco había remanentes de una visión organicista que reducía la conciencia "a un sistema de percepción o repositorio de nonemas" (Andrade, 1939, p. 148). Freud terminaba siendo "incoherente e ilógico" por su estrecha y mecanicista conceptualización de los fenómenos psicológi- 
cos (Andrade, 1939, p. 149). "El dualismo consciencia-inconsciencia es perjudicial -dice entonces Andrade- porque contiene vestigios peligrosos de una concepción estática de la vida psíquica”, que impide entender lo imaginario, lo fantasioso o lo onírico como "manifestaciones profundas de una especie de energía que crea en nosotros la percepción consciente" (Andrade, 1939, p. 151).

En una curiosa maniobra genealógica, el pensador brasileño encontraba los orígenes del dualismo freudiano nada menos que en Descartes. Y frente a ese dualismo reivindicaba a los neokantianos de fines del siglo XIX e, incluso, a Bergson, ya que estos no ponían en duda "el vínculo sustancial, fundido y amalgamado de la indestructible unidad de la persona humana" (Andrade, 1939, pp. 186-187). De ahí la importancia que Andrade concedía a la poderosa corriente sociológica y antropológica que, de la mano de Gilberto Freyre, se abría paso en el pensamiento brasileño. Con Casa grande y senzala (1934), Sobrados e mucambos (1936) y Nordeste (1937), Freyre había logrado naturalizar el marco teórico "histórico-cultural" de las ciencias sociales funcionalistas, especialmente asociado a la obra de Franz Boas, conteniendo el racismo de la generación anterior, de Nina Rodríguez y Oliveira Viana, a quienes Andrade veía demasiado atados al paradigma "neolamarkista" de la "herencia de los caracteres adquiridos", sostenido por autores como Weismann, Packard y Cope (Andrade, 1939, pp. 49-50). La crítica del funcionalismo británico y estadunidense servían a Andrade para criticar el "puritanismo intolerante de la colonización anglosajona" y, de paso, atraer el enfoque histórico-cultural de Freyre a las tesis del mestizaje del varguismo.

El Estado Novo, tras la constitucionalización "polaca" de 1937, dio un giro en la política cultural y educativa en el sentido nacionalista de la nueva doctrina de régimen. Sergio Miceli destaca el papel de ministros como Gustavo Capanema en Educación y Cultura y de Rodrigo y Mario de Andrade en el Servicio de Patrimonio Histórico y Artístico Nacional (Miceli, 1984, pp. 2330). El encargo que el Departamento de Imprenta y Propaganda dio a Almir de Andrade de editar la revista Cultura Política se enmarca en esa subordinación de la política cultural a la doctrina del régimen varguista. Una de las primeras decisiones de Andrade fue atraer al equipo de redacción a intelectuales afines o no a Vargas, como el escritor Graciliano Ramos, que había estado preso a finales de los años treinta, el filósofo bergsoniano Azevedo Amaral, el periodista Cassiano Ricardo, director del diario A Manhá, que tomaban distancia tanto del modernismo de fines del siglo XIX como del vanguardismo de los veinte (Silva de Paiva, 2009). 
Esos y otros autores como Silvio Peixoto, Severino Sombra, Jaime de Barros y Belfort Oliveira, fueron incorporados a los trabajos del Departamento de Imprenta y Propaganda del varguismo, una institución concebida para nuclear la intelectualidad orgánica del primer gran experimento populista de América Latina. Cada número de la revista Cultura Política incluía glosas de los principales artículos de la Constitución de 1937, redactada por el jurista antiliberal Francisco Campos. El eje conceptual del cambio constitucional del "Estado novo", según Andrade, era el de "democracia social y evolutiva", una expresión que condensaba el propósito de rebasar la "democracia liberal" heredada del siglo xix y que había colapsado con la "República vieja” en 1930. En el primer número de Cultura Política, dicho concepto de "democracia social y evolutiva" se plasmaba de esta manera:

Las instituciones sociales y políticas son procesos que se desarrollan en el tiempo. No es posible forzar transformaciones prematuras. Vivimos en un mundo convulso, en el que la democracia prevalecerá, pero la democracia es una institución viva, que evoluciona con las mutaciones de la vida, es un ideal de solidaridad humana, con respecto al trabajo y los frutos del trabajo, de lealtad y sinceridad de cooperación de todos los hombres para el bien común (Andrade, 1945, p. 7).

Y agregaba aquel editorial:

El Estado debe ser socialmente útil. La democracia procura una forma superior de convivencia y solidaridad humana. Sus objetivos son distribuir bienes sociales en la medida de las necesidades y capacidades de cada quien, asegurar el orden para una mejor eficiencia del trabajo, fortalecer los vínculos de solidaridad económica, afectiva y moral entre los individuos y las clases, disciplinar las fuerzas económicas y políticas para que no proliferen los individualismos y pueda haber mayor justicia entre los hombres, equidad y respeto y comprensión mutua (Andrade, 1945, p. 8).

Andrade defendía una noción integral de la vida intelectual, en la que se entrelazaban la economía y la política, la literatura y el folclore, las artes y las ciencias, las tradiciones y las costumbres, la filosofía y la técnica (Andrade, 1945, p. 5). Esa integralidad, que intentaba ser captada por el concepto de "cultura política", suponía, a su juicio, una "visión humana estereoscópica" 
(Andrade, 1945, p. 11). El Estado aparecía en esa ideología como el organismo integrador de todas las funciones del cuerpo social, lo cual era reflejado por Andrade y otros articulistas de la revista en textos sobre el corporativismo agrícola, el diseño de una monumentalística nacional en el espacio público, la centralización del gobierno y el rol de los municipios (Andrade, 1945, pp. 15-17).

Según Azevedo Amaral (1941, p. 157), el integralismo varguista era resultado de una evolución histórica que superaba, primero, la política imperial, luego la política republicana, y que desembocaba en la que llamaba la "Revolución Brasileira” de los treinta, cuya más nítida conceptualización era la Carta Magna del 10 de noviembre de 1937. Silvio Peixoto, por su parte, pensaba que esa tradición histórica describía una lógica ascendente del principio de la "unidad nacional" en tres fases: el imperio, la república y la revolución (Peixoto, 1941, p. 175). Mientras que Severino Sombra (1941, p. 42) sugería que el nacionalismo democrático del Estado Novo era obra de un proceso de maduración del "derecho natural racionalista" que había roto, finalmente, con los rezagos del racionalismo borbónico.

En cada número de Cultura Política se transcribía un artículo de la Constitución de 1937 -sobre la propiedad, el municipio, el poder judicial, el trabajo manual, la ideología del nacionalismo democrático-y, a la vez, el escritor Graciliano Ramos comentaba los cuadros de costumbres del Nordeste brasileño. En esas crónicas que luego se reunieron póstumamente en los volúmenes Linhas Tortas (1962) y Viventes das Alagoas (1962), Ramos presentaba los desiertos y las llanuras de los cangaceiros como un mundo puro, que simbolizaba la identidad nacional postulada por el varguismo. Sin el tono de denuncia de la novela Vidas secas (1938), las crónicas de Ramos en Cultura Política revestían al Estado Novo de un discurso de autenticidad cultural, que rebajaba los acentos desarrollistas de la ideología populista.

Otros autores de la revista como el propio Andrade y Jaime de Barros se encargaban de insertar ese discurso de la identidad nacional en un americanismo de corte hemisférico (Barros, 1941a, p. 34; 1941b, p. 60). A diferencia de algunos textos de Andrade de los años treinta, críticos del protestantismo anglosajón, ahora, en el contexto de la segunda guerra mundial, la visión de Estados Unidos era moderadamente positiva. El propio Vargas había transmitido ese cambio de percepción sobre Estados Unidos en sus diarios, donde comentaba una comunicación paralela con Benito Mussolini y Franklin D. Roosevelt, claramente favorable al segundo, en quien veía, no sin "hipérboles criollas", la "simpatía irradiante y el pacifismo sincero" y la "oratoria clara, 
simple, pero llena de imaginación" del pueblo americano (Vargas, 1995, p. 563). Vargas y sus intelectuales rechazaban la "imprevisibilidad de las democracias liberales" en la segunda guerra, y achacaban su crisis al agotamiento del modelo individualista del siglo xIX, pero temían más al fascismo italiano y, sobre todo, al nazismo alemán (Vargas, 1995, pp. 313-317).

En ensayos de Andrade de los años cuarenta, como Formação da sociologia brasileira (1941) o Contribuição a História administrativa do Brasil (1949), la neutralidad varguista ante el conflicto mundial y la naciente guerra fría adoptaba un cariz historicista, en el que la equidistancia frente a las superpotencias hegemónicas era explicada por una tradición imperial venida a menos. Con la Revolución del 30, aseguraba Andrade, el sentido profundo de la evolución social brasileña cristalizaba en el Estado (Andrade, 1949, p. 9). Había indicios de una exégesis de aquella evolución en discursos presidenciales de Campos Sales y Rodrigues Alves a principios del siglo xx, pero con Vargas y el Estado Novo, ese evolucionismo, de raíz sociológica, superaba la prueba de una revolución, que era una "lección de realismo" (Andrade, 1949, p. 9). Tanto en el espesor sociológico del discurso de la identidad como en un americanismo hemisférico, abierto al diálogo con Estados Unidos y Europa, el varguismo se diferenciaba del llamado "tercerismo" peronista, más enfáticamente opuesto a la hegemonía anglosajona en el Atlántico.

Existe una notable coincidencia, aunque también matices, entre las ideas manejadas por Andrade en Cultura Política y la que trasmitían, desde 1936, los jóvenes editores argentinos de Cuadernos de FORJA, la principal publicación de la así llamada Fuerza de Orientación Radical de la Joven Argentina. En el primer número de aquella publicación se plasmaba una declaración de fe nacionalista: "FORJA quiere afrontar los problemas argentinos con criterios argentinos, porque considera que el vicio más funesto que padecemos es la entrega ominosa de la economía nacional a la colonización de las grandes potencias imperialistas". ${ }^{2}$ Más adelante los miembros de la Redacción (Gabriel de Mazo, A. Gutiérrez Diez, José Gabriel, Homero Manzione, Arturo Jauretche, Jorge del Río, José D. Espeche, Luis Dellepiane...) afirmaban encontrarse libres de "influencias banderizas exóticas", como el "sovietismo y el

2 "Los Cuadernos de ForJa", Cuadernos de FORJA, año I, núm. 1, 25 de mayo de 1936, Buenos Aires, p. 4. 
fascismo", y "puesta el alma en lo más noble de las tradiciones igualitarias" argentinas. $^{3}$

En los números de Cuadernos de FORJA se proyectó un nacionalismo argentino que buscaba más continuidad que ruptura con el republicanismo de Hipólito Yrigoyen y, a la vez, se colocó el problema de los recursos naturales, especialmente el petróleo, y de los servicios públicos (gas, transporte, electricidad, ferrocarriles, empréstitos...) bajo el radio de acción del Estado. ${ }^{4}$ Los ensayos de Luis Dellepiane, en aquella publicación, eran especialmente reveladores de lo que podría entenderse como una insinuación de eje populista latinoamericano dentro de la geopolítica mundial. Así como Dellepiane llamaba a asimilar las enseñanzas de la expropiación petrolera mexicana, no ocultaba simpatías hacia el giro soberanista del varguismo y la lucha de la República Española contra el fascismo, ni críticas elocuentes al "imperialismo inglés", la "plutocracia yanqui" y la "dictadura staliniana de la Eurasia soviética" (Dellepiane, 1939, pp. 4-8).

Dellepiane y los intelectuales del grupo Fuerza de Orientación Radical de la Joven Argentina (FORJA) sostenían en 1939 que en el contexto de la guerra inminente, "Moscú y Berlín estaban más cerca de lo que parece", y llamaba a replantear el liderazgo del "espíritu americanista" desde el Sur del continente (Dellepiane, 1939, pp. 6 y 8). El lenguaje de aquellos jóvenes argentinos, como el de los escritores y científicos sociales reunidos por Almir de Andrade en Cultura Política, partía de la premisa histórica de que el varguismo y el peronismo eran movimientos sociales y políticos que adaptaban a las condiciones suramericanas el "contenido antimperialista de la Constitución de 1917 en México” (Dellepiane, 1938, p. 19). La "lección de Méjico”, especialmente tras la expropiación petrolera de Lázaro Cárdenas, era un estímulo al "deber revolucionario" de radicalizar la izquierda argentina, sobre todo la izquierda de la Unión Cívica Radical, una corriente que veían destinada a interpelar, parale-

3 "Los Cuadernos de ForJA", Cuadernos de FORJA, año I, núm. 1, 25 de mayo de 1936, Buenos Aires, p. 4.

${ }^{4}$ Gabriel de Mazo, "El pensamiento escrito de Yrigoyen", Cuadernos de FORJA, año I, núm. 2, 3 de julio de 1936, Buenos Aires, pp. 7-21. Véase también a A. Gutiérrez Diez, "La coordinación de los transportes", Cuadernos de FORJA, año I, núm. 3, octubre de 1936, Buenos Aires, pp. 6-11; Raúl Scalabrini Ortiz y Luis Dellepiane, "Petróleo e imperialismo. El ejemplo de Méjico y el deber argentino", Cuadernos de FORJA, año II, núm. 4, septiembre de 1938, Buenos Aires, pp. 15-27; Jorge del Río, "El problema de la electricidad. Estructura del trust" y "El servicio público del gas: inconvenientes de su oficialización”, Cuadernos de FORJA, año II, núm. 5, octubre de 1938, Buenos Aires, pp. 10-22. 
lamente, al imperialismo angloamericano, el fascismo europeo y el frentismo prosoviético del comunismo internacional (Dellepiane, 1938, p. 19).

\section{SCALABRINI ORTIZ: DE LA NADA A LA PROFECÍA}

El uso del concepto de Revolución en el peronismo arranca con la resemantización del evento del golpe militar de junio de 1943. En un principio, los líderes del movimiento, como los generales y ministros de Guerra, Pedro Pablo Ramírez y Edelmiro Julián Farrel, negaban que en Argentina se hubiese producido una revolución. El primero, por ejemplo, decía: "yo no he llevado a cabo ninguna revolución, porque de hecho no ha habido ninguna revolución. El ejército actuó no en una revolución, sino para proveer a Argentina de una solución al gran problema institucional del país, cuando su orden constitucional estaba corrompido por completo" (Groppo, 2009, p. 181). El importante intelectual católico Gustavo Franceschi, en cambio, se acercaba a la formulación del golpe como Revolución cuando afirmaba que "no se trataba de una revolución política ni tampoco de un cuartelazo, estamos enfrentando un fenómeno más profundo y sustancial, no es solamente sustituir a unos hombres por otros" (Groppo, 2009, p. 184). Franceschi, editor de la revista católica Criterio, sostenía que la revolución tenía que ser social, no meramente política como en tiempos de Hipólito Yrigoyen: debía enfrentarse a la "politiquería" con una ampliación de la base social de la política.

Es el propio Perón quien definirá más claramente el golpe de junio del 43 como una revolución social o como una revolución de "espíritu social" (Groppo, 2009, p. 195). El nuevo ministro de Trabajo y Previsión Social se refería al manifiesto militar de junio de 1943 como "proclama revolucionaria" y presentaba al llamado Grupo de Unificación como un agente de un cambio más sustancial que el que transmitían los documentos oficiales. Con evidente eficacia, Perón transformó simbólicamente el golpe en Revolución por medio de una retórica que ponía énfasis en la decadencia de la clase política de la República y, a la vez, en la necesidad de situar el proyecto de gobierno en sintonía con las demandas sociales de los trabajadores argentinos. Es interesante observar el surgimiento de aquel lenguaje populista en los documentos militares argentinos, que Perón conocía muy bien por haber estudiado la historia de dicha institución. 
En una conferencia en el Colegio Nacional de la Universidad de la Plata, en junio de 1944, conmemorando el primer aniversario del golpe, Perón sugería que la asonada militar del año anterior era una respuesta a la coyuntura internacional de la segunda guerra mundial, que podía "encender luchas fratricidas" en el continente americano, a pesar de lo lejos que estaba de Europa (Perón, 1973, p. 32). Luego, en una orden del coronel Perón, como ministro de Guerra, a los oficiales del ejército, se sostenía que la guerra era la ocasión para articular la "neutralidad política", la "economía social" y la "independencia económica" como objetivos básicos de un programa integral de renovación del Estado argentino (Perón, 1973, pp. 96-108). Allí el líder argentino hablaba claramente de lo que sucedía en Argentina como una revolución que se encaminaba hacia su constitucionalización o, lo que es lo mismo, hacia su final: "la Revolución entra en su etapa final y el gobierno encara resueltamente la normalización constitucional, levantando el estado de sitio y aprestándose a convocar al pueblo de la República para la elección de sus mandatarios" (Perón, 1973, p. 95).

La Secretaría de Trabajo y Previsión Social era, según Perón: "un jalón que se clava en la hora constitutiva inspirada en la Revolución del 4 de junio" (Perón, 1997, p. 115). No era aquella idea retrospectiva o a posteriori, incorporada al relato sobre la ascensión del peronismo al poder, sino una certeza constatable en los discursos del entonces secretario de Trabajo. Al facilitar el despliegue de la nueva política obrera, el viejo Grupo de Unificación militar contribuía a una resignificación de la proclama, más bien técnica, del 4 de junio de 1943, como punto de partida de una política social de Estado. Con Perón en la Secretaría de Trabajo iniciaba, propiamente, la "era de la política social" en la historia argentina, lo que representaba, ni más ni menos, un cuestionamiento a fondo de las premisas liberales y republicanas predominantes en la nación suramericana, entre Sarmiento e Yrigoyen (Perón, 1997, pp. 47-48, 117-122 y 515-516). Dicha política social arrancaba como una colonización populista del movimiento obrero, especialmente contra los comunistas, pero aspiraba, a la vez, a una reformulación de la plataforma liberal del Estado, más eficaz que la propuesta por el comunismo:

Los patrones, los obreros y el Estado construyen las partes de todo problema social, y quienes lo resuelvan tendrán el mérito de impedir la intromisión en las cuestiones gremiales de la especulación política y el confusionismo generalizado [...] El Estado argentino intensificará su deber social, no puede ser 
un espectador, debe involucrarse en la defensa de los intereses y la mejoría material de los obreros, frente a la patronal (Perón, 1997, p. 113).

Entre 1943 y 1946, cuando Perón pasa por las secretarías de Trabajo y Guerra y el cargo de vicepresidente, hasta el lanzamiento de su candidatura tras el fin de la guerra, el programa populista va perfilándose como una apuesta por la reconfiguración del sistema político. Perón triunfó con el apoyo de tres partidos de reciente creación, el Partido Laborista, el Partido Independiente y una escisión de Unión Cívica Radical llamada Junta Renovadora. Aquella alianza daría lugar a la corriente propiamente llamada "justicialista" o "peronista", pero que inicialmente se llamó Partido Unido de la Revolución y luego Partido Peronista. De manera que hasta los años que siguieron a la primera elección de Perón, el término Revolución estaba incorporado como uno de los principales conceptos políticos del nuevo régimen. Durante la campaña electoral, en los primeros meses de 1946, Perón dio forma a esa asimilación por medio del enunciado de su proyecto "orgánico":

¿Qué es un gobierno orgánico? Es una agregación de fuerzas sólidamente aglutinadas que tiene a su frente a un estadista, que no debe ser forzosamente ni un genio ni un sabio, sino un hombre a quien la naturaleza ha dotado de una condición especial para abarcar un panorama completo que otros no ven. Ese hombre tiene dos o tres discípulos para que cuando muera haya quien lo prolongue en el tiempo y el espacio. Detrás de ellos viene la plana mayor del partido, que tiene ocho, diez, veinte especialistas o técnicos para cada rama del Estado, que son los candidatos a ser ministros, se preparan desde el llano con estudio y sacrificio, y no hay problema del país, por insignificante que sea, que en su rama ni lo dominen y tengan la solución, para que, al llegar al Gobierno, abran el cajón de su escritorio, saquen el plan y ordenen su inmediata ejecución (Perón, 1997, pp. 18-19).

En un discurso en Santa Fe, en febrero de 1946, Perón agregaba que una estructura así, que repartía sus funciones entre el líder, los técnicos, el partido y la masa, nunca había existido en Argentina. Y agregaba que su puesta en práctica, por medio de una serie de reformas "orgánicas" bien pensadas, era una confirmación del carácter "revolucionario" del golpe de junio de 1943. El argumento revolucionario y el reformista se mezclaban en la retórica organicista de Perón, creando tautologías en la que el movimiento se definía como 
revolucionario por ser reformista y reformista por ser revolucionario. Todos los hitos del peronismo, antes de la campaña presidencial, como la revuelta de junio de 1943 o la movilización pacífica a favor de Perón en octubre de 1945, cuando el líder fue encarcelado por el general Farrel, adquirían un nuevo sentido providencial en el lenguaje de Perón:

En la mente de quienes concibieron y gestaron la Revolución del 4 de junio estaba fija la idea de la redención social de nuestra Patria. Este movimiento inicial no fue una "militarada" más, no fue un "golpe cuartelero" más, como algunos se complacen en repetir: fue una chispa que el 17 de octubre encendió la hoguera en la que van a crepitar hasta consumirse los restos del feudalismo que aún asoma por la tierra americana (Perón, 1997, p. 27).

Ya desde entonces Perón comienza a trazar los presupuestos de lo que será el revisionismo histórico argentino, estudiado por Tulio Halperin Donghi, cuando sostiene que el dilema en Argentina no es "entre libertad y tiranía, entre Rosas y Urquiza, entre democracia y totalitarismo", sino "entre justicia e injusticia social" (Perón, 1997, p. 28). Durante el primer gobierno, entre 1946 y 1949, aquel proyecto, condensado en el "primer plan quinquenal", fue difundido intensamente en todos los foros imaginables. Perón hablaba con todos: líderes sindicales, trabajadores de fábricas, los empleados de aduanas, los miembros de los clubes de esgrima, los estibadores del puerto de San Nicolás o la elite de Buenos Aires, reunida en el teatro Colón. El decálogo del "plan quinquenal" era resumido por Perón, ante esos auditorios heterogéneos, con un lenguaje llano, que rebajaba los aspectos técnicos de la planificación económica, y traducía en términos soberanistas y justicieros el programa revolucionario del gobierno.

Es en esos años, previos a la Constitución de 1949, que algunos intelectuales cercanos al grupo FORJA, de la Unión Cívica Radical yrigoyenista, como Arturo Jauretche y, sobre todo, Raúl Scalabrini Ortiz, se acercaron al peronismo. A diferencia de los miembros centrales de FORJA, como el propio Jauretche, Homero Manzi o Gabriel del Mazo, que mantuvieron siempre su lealtad a la Unión Cívica Radical, Scalabrini Ortiz abrazó el peronismo con toda la carga fundacional que intentaron darle los artífices del golpe militar del Grupo de Oficiales Unidos (Gou) el 4 de junio de 1943. Tres años antes, en 1940, este poeta y agrónomo corrientino había publicado, en forma de libros, dos ensayos, Política británica en el Río de la Plata (1940) e Historia de los ferro- 
carriles argentinos (1940), que hacían votos por una regeneración nacional en Argentina, basada en la recuperación de la soberanía económica del país, pero que habían aparecido en una versión preliminar en los ya citados Cuadernos de FORJA, órgano de aquel grupo. ${ }^{5}$

En el primero de aquellos ensayos, Scalabrini hacía su contribución al revisionismo histórico cuando argumentaba que la historia política argentina, desde la generación de 1810, era la historia de la dependencia de la Gran Bretaña. Con la excepción de Mariano Moreno, decía, los padres fundadores adoptaron "las doctrinas corrientes en Europa y se adscribieron a un libre cambio suicida" (Scalabrini Ortiz, 1965a, p. 11). Aquel legado liberal y, por liberal, antinacional y antipopular, había sido altamente costoso para el país. La "realidad argentina" representaba un "imperativo espiritual" para las clases gobernantes (Scalabrini Ortiz, 1965a, pp. 9-13). Debía pasarse de la entrega a los intereses extranjeros, como "factor primordial del antiprogreso", a una "economía al servicio de la esperanza" (Scalabrini Ortiz, 1965a, pp. 254-286 y 358-359). La tradición liberal había depreciado tanto las condiciones de vida del pueblo argentino que derechos sociales básicos, como la alimentación, la vivienda y el vestido debían ser considerados como "problemas nacionales" (Scalabrini Ortiz, 1965a, p. 358).

En el segundo libro, la Historia de los ferrocarriles argentinos, Scalabrini utilizaba la crisis de la red ferroviaria del país como metáfora de la sangría de la riqueza nacional. La colonización había creado "redes venales" que depredaron los recursos naturales de la nación y enriquecieron las arcas coloniales e imperiales, especialmente las británicas. Pero el lenguaje nacionalista de Scalabrini Ortiz comulgaba más con un "americanismo", muy propenso a la defensa de la herencia de los migrantes e hijos de migrantes en el Río de la Plata, que a un argentinismo al estilo de Ezequiel Martínez Estrada en su gran ensayo Radiografía de la pampa (1933). Las fronteras de ese americanismo llegaban hasta México, no más allá, en un sentido deliberadamente restrictivo, que excluía a Estados Unidos y Canadá, a razón de una "unidad de idiomas, razas fundadoras, religiones y costumbres" (Scalabrini Ortiz, 1940, p. 15). En las palabras preliminares de su ensayo, Scalabrini (1940) anotaba:

${ }^{5}$ Raúl Scalabrini Ortiz, "La política británica en el Río de la Plata. Las dos políticas: la visible y la invisible", Cuadernos de FORJA, año I, núm. 1, 25 de mayo de 1936, Buenos Aires, pp. 5-19; Raúl Scalabrini Ortiz, "Historia del ferrocarril de Córdoba", Cuadernos de FORJA, año II, núm. 6-7, noviembre de 1938, Buenos Aires, pp. 3-62. 
Europa jamás buscó en América el establecimiento de una filialidad. Fue hostil y casi cruel con lo autóctono, primero, con lo asimilado, después. Europa solo quiso extraer oro, al principio. Minerales, más tarde. Materia prima y alimentos, ahora. De fuerza y compulsión se valió antes. De habilidad y astucia financiera, actualmente. De todos modos, fue de provecho la finalidad. Por eso el estudio del factor económico es fundamental en las relaciones de Europa y América (p. 11).

Y agregaba:

Lo indiscutiblemente americano fue tronchado en América [...] América es un sentimiento, un estado del alma, no una materialidad y menos una consanguinidad. Ser poroso para ese sentimiento y no impermeable puede únicamente motivar una jactancia de americanidad. El simple nacer aquí de padres aquí nacidos es un ocurrimiento de índole civil no trascendente. Hijos de extranjeros fueron Moreno, San Martín y Belgrano, ejecutores de la primera liberación americana del Río de la Plata (p. 14).

En el paisaje argentino, según Scalabrini (1940), no había esos elementos de autenticidad que deslumbraban a otros escritores nacionalistas, como el propio Martínez Estrada o Graciliano Ramos en Brasil, sino desolación:

Pueblo pobre: así es el nuestro. Llanuras insípidas en que la imaginación trabaja constantemente, ríos inhumanos, montañas inaccesibles y estériles conforman la patria. El fruto de sus pampas es para otros y para otros sus carnes y sus pensamientos. Estamos de prestado sobre la tierra que aún está por conquistar y sobre la que tenemos apenas una leve apariencia de dominio político, no real (p. 15).

Esto escribía el joven poeta y agrónomo en 1940. Seis años después, en medio de la movilización peronista, que culminará al año siguiente con la Constitución, Scalabrini ha renacido. En el que es, tal vez, su libro de ensayos más cuidado, desde un punto de vista estilístico, Tierra sin nada, tierra de profetas (1946), el escritor rinde testimonio de la metamorfosis que ha experimentado por efecto de la promesa peronista y su contacto directo con las multitudes del justicialismo. Cuenta que una tarde de octubre de 1945, mientras que un sol a plomo caía sobre la Plaza de Mayo, de pronto se vio arrastrado 
por enormes columnas de obreros, que lo convencieron de que una nueva "muchedumbre heteróclita" asumía los destinos de la nación (Scalabrini Ortiz, 1946, p. 33). La experiencia, narrada en tono epifánico por el escritor, daba pie a toda una apología de la fusión entre el individuo y la masa:

En las cosas humanas el número tiene una grandeza particular por sí mismo. En ese fenómeno majestuoso a que asistía, el hombre aislado es nadie, apenas algo más que aterido grano de sombra que a sí mismo se sostiene y que el impalpable viento de las horas desparrama. Pero la multitud tiene un cuerpo y un ademán de siglos. Éramos briznas de multitud y el alma de todos nos redimía. Presentía que la historia iba pasando junto a nosotros y nos acariciaba suavemente como la brisa fresca del río (p. 35).

Es entonces que el nacionalismo se acerca a un criollismo -o a un nativismo-, y a una defensa del "espíritu de la tierra" que es traducida en términos de política económica como un avance acelerado hacia el control estatal de los recursos naturales, la banca y los servicios públicos (p. 35). Aclaraba Scalabrini que ese "espíritu de la tierra" era "tenso, corpóreo y multifacetado", pero que su experiencia sólo podía alcanzarse por medio de una disolución del individuo en la masa, que implicaba la ruptura radical no sólo con la tradición liberal, tanto de la filosofía como de la economía, sino con corrientes de pensamiento de la segunda posguerra como el psicoanálisis y el existencialismo (p. 35). Se llegaba así a una confluencia intelectual bastante precisa entre el antiliberalismo varguista de Andrade y el peronista de Scalabrini, aunque con la peculiaridad de que en el segundo caso la discontinuidad se extendía a los proyectos keynesianos y cepalinos que impulsaban economistas como Raúl Prebisch.

En escritos posteriores al suicidio de Vargas en 1954 y al golpe militar contra Perón de 1955, autodenominado, por cierto, "Revolución Libertadora", los dos autores asumieron en sus escritos un duelo similar. Pero mientras Andrade intentaba reconciliar el legado del varguismo con las tesis de la Cepal, Scalabrini en los artículos valientemente opositores contra los gobiernos de Eduardo Lonardi y Pedro Eugenio Aramburu, reunidos luego en el libro Bases para la reconstrucción nacional (1965), acusó a Prebisch de ser agente de la inteligencia británica y denunció sus "planes" e "informes" como intentos de desmantelar la política económica peronista (Andrade, 1973, p. 21; Scalabrini Ortiz, 1965b, p 23). Scalabrini murió en 1959, por lo que no llegó a constatar 
el impacto radicalizador de la revolución cubana sobre la izquierda peronista. Andrade, que sobrevivió al golpe de Estado contra Joao Goulart y al giro marxista del populismo brasileño, llegó a comulgar con las tesis anticomunistas de la guerra fría.

\section{CONCLUSIÓN}

A través de la obra de Almir de Andrade y Raúl Scalabrini Ortiz hemos ilustrado la forma en que el campo intelectual de viejas democracias oligárquicas en crisis interviene en el despliegue de un discurso de legitimación para el nuevo régimen populista. Desde las experiencias clásicas del varguismo y el peronismo, en los años treinta y cuarenta, esos procesos están ligados a un uso del concepto de Revolución desde las elites del cambio de régimen que no reúne los rasgos característicos de otras revoluciones como la mexicana, la rusa o la china: levantamiento armado popular, destrucción del orden previo, alteración de jerarquías sociales. El concepto de Revolución, sin embargo, se vuelve central para la legitimación del nuevo Estado, como parte de un lenguaje político que transmite el sentido de reconstitución jurídica en tanto "necesidad histórica" (Koselleck, 2012, p. 169).

Publicaciones como Cultura Política en Brasil o Cuadernos de FORJA en Argentina constituyeron, además, plataformas del saber en las que ideólogos de la izquierda populista entablaban diálogos significativos con el campo de las ciencias sociales, tal y como sucedía en las redes de otras izquierdas, especialmente las marxistas, comunistas y nacionalistas revolucionarias. ${ }^{6}$ Esta aproximación pone en cuestión, por tanto, los enfoques excepcionalistas que tienden a asociar el populismo con un grado cero de la ideología, que operaría en torno a significantes vacíos más que a verdaderos resortes doctrinales para la acción política.

Buena parte de la historiografía y la teoría política se resiste a considerar aquellas publicaciones y sus líderes intelectuales dentro de la izquierda latinoamericana. Incluso en el caso de Cultura Política, la revista brasileña de los años cuarenta, observamos acentos y énfasis en torno a la soberanía nacional, la justicia social y la integración racial, bien ubicados en otras tradiciones (2009).

${ }^{6}$ Véanse, entre otros, Corral, Stanton y Valender (2018); Crespo (2010); Petra (2017); Pita 
de izquierda, pero que se le escamotean por un desprecio a enfoques funcionalistas $u$ organicistas propios de la época. Los prejuicios ante el imaginario político de aquellos populismos conducen a una subvaloración de la densidad ideológica de los mismos, que incurre en una equivocada lectura de sus premisas teóricas.

\section{LISTA DE REFERENCIAS}

Amaral, A. (1941). Realismo político y la democracia. Cultura Política, 1, 157.

Andrade, A. de (1933). A verdade contra Freud. Río de Janeiro: Schmidt Editor.

Andrade, A. de (1939). Aspetos de cultura brasileira. Río de Janeiro: Schmidt Editor.

Andrade, A. de (1945). Cultura política en su nueva fase. Cultura Política. Revista Mensual de Estudios Brasileños, $v(5), 1$.

Andrade, A. de (1949). Contribuição a História administrativa do Brasil. Río de Janeiro: Livraria José Olympio Editora.

Andrade, A. de (1973). O capital nos sistemas económicos. Río de Janeiro: Editora Rio.

Barros, J. de (1941a). La política de Brasil en América. Cultura Política, 1, 34.

Barros, J. de (1941b). La influencia de las guerras europeas en el destino de América. Cultura Política, 5, 60.

Bergel, M. (2018). ForJA: un pensamiento de la desconexión. En C. Altamirano (ed.), La Argentina como problema: temas, visiones y pasiones del siglo xx. Buenos Aires: Siglo XXI.

Corral, R., Stanton, A. y Valender, J. (eds.) (2018). Laboratorios de lo nuevo. Revistas literarias de México, España y el Río de la Plata en la década de los 20. México: El Colegio de México.

Crespo, R. (2010). Revistas en América Latina. Proyectos literarios, políticos y culturales. México: Universidad Nacional Autónoma de México.

Dellepiane, L. (1938). El petróleo de Méjico y el deber argentino. Cuadernos de FORJA, II(4).

Dellepiane, L. (1939). Conducta argentina ante la crisis de Europa. Cuadernos de FOR$J A, I I(9)$.

Finchelstein, F. (2018). Del fascismo al populismo en la historia. Buenos Aires: Taurus.

Fiorucci, F. (2011). Intelectuales y peronismo. Buenos Aires: Biblos.

Germani, G., di Tella, T. S. e Ianni, O. (1973). Populismo y contradicciones de clase en América Latina. México: Era. 
Groppo, A. J. (2009). Los dos príncipes: Juan D. Perón y Getulio Vargas. Buenos Aires: Universidad Nacional Villa María.

Ianni, O. (1975). La formación del Estado populista en América Latina. México: Era.

Knight, A. (1998). Populism and neo-populism in Latin America, especially in Mexico. Journal of Latin American Studies, 30(2), 223-248. DoI: https://doi.org/10.1017/ S0022216X98005033

Koselleck, R. (2012). Historias de conceptos. Estudios sobre semántica y pragmática del lenguaje político y social. Madrid: Editorial Trotta.

Laclau, E. (1978). Política e ideología en la teoría marxista. Capitalismo, fascismo y populismo. México: Siglo XXI.

Laclau, E. (2005). La razón populista. Buenos Aires: Fondo de Cultura Económica.

Lippi Oliveira, L., Pimenta, M. y Castro Gomez, Á. M. (1982). Estado Novo: ideologia e poder. Río de Janeiro: Zahar.

Mio Salla, T. (2017). Graciliano Ramos e a cultura política. Mediação editorial e construção do sentido. São Paulo: Edusp.

Miceli, S. (ed.) (1984). Estado e cultura no Brasil. São Paulo: IDESP.

Mudde, C. (2004). The populist Zeitgeist. Government and Opposition, 39(4), 541-563. DOI: https://doi.org/10.1111/j.1477-7053.2004.00135.x

Peixoto, S. (1941). La tradición política del principio de unidad nacional. Cultura Política, 3, 175.

Perón, J. D. (1997). Obras completas (8 tt.). Buenos Aires: Fundación Universidad de la Producción y el Trabajo/Fundación de la Universidad a Distancia "Hernandarias".

Perón, J. D. (1973). Diálogo entre Perón y las fuerzas armadas. Buenos Aires: Centro de Documentación Justicialista.

Petra, A. (2017). Intelectuales y cultura comunista. Itinerarios, problemas y debates en la Argentina de la postguerra. Buenos Aires: Fondo de Cultura Económica.

Pita, A. (2009). La Unión Latinoamericana y el Boletín Renovación. Redes de intelectuales y revistas culturales en la década de los 20. México: El Colegio de México.

Scalabrini Ortiz, R. (1940). Historia de los ferrocarriles argentinos. Buenos Aires: Editorial Reconquista.

Scalabrini Ortiz, R. (1946). Tierra sin nada, tierra de profetas. Devociones para el hombre argentino. Buenos Aires: Editorial Reconquista.

Scalabrini Ortiz, R. (1965a). Política británica en el Río de la Plata. Buenos Aires: Editorial Plus Ultra.

Scalabrini Ortiz, R. (1965b). Bases para la reconstrucción nacional. Buenos Aires: Plus Ultra.

Sigal, S. (1991). Intelectuales y poder en la década del sesenta. Buenos Aires: Puntosur. 
Silva de Paiva, V. da (2009). La organización del campo intelectual en el Estado Novo (Brasil, 1937-1945). Recuperado de http://cdsa.aacademica.org/000-008/139.pdf

Sombra, S. (1941). El absolutismo moderno y el advenimiento del derecho natural racionalista. Cultura Política, 9.

Stanley, B. (2008). The thin ideology of populism. Journal of Political Ideologies, 13(1), 95-110. DoI: https://doi.org/10.1080/13569310701822289

Trindade, H. (1974). Integralismo. O fascismo brasileiro na década de 30. São Paulo: Difusão Europeia do Livro.

Vargas, G. (1995). Diario. 1930-1936 (2 tt.). Río de Janeiro: Fundação Getúlio Vargas.

Velloso, M. P. (2003). Os intelectuais e a política cultural da Estado Novo. En J. Ferreira y L. de A. Neves Delgado, O Tempo do Nacional-estatismo: do início da década de 1930 ao apogeu do Estado Novo. Río de Janeiro: Civilização Brasileira.

\section{OTRAS FUENTES}

\section{Revistas}

Cultura Política (1940-1943)

Cuadernos de FORJA (1936-1942)

\section{Bibliografía}

Amaral, A. (1941a). La evolución de la política imperial. Cultura Política, 2, 31.

Amaral, A. (1941b). La evolución de la política republicana. Cultura Política, 3, 154.

Amaral, A. (1941c). La revolución brasileira. Cultura Política, 5, 133.

Andrade, A. de (1941a). Política y cultura. Cultura Política, 2, 5.

Andrade, A. de (1941b). La soberanía internacional de Brasil. Cultura Política, 3, 5.

Andrade, A. de (1941c). Brasil y la centralización del nuevo gobierno. Cultura Política, 4,5 .

Andrade, A. de (1941d). Democracia social y economía. Cultura Política, 6, 161.

Andrade, A. de (1941e). Los grandes trazos de la Constitución del 10 de noviembre de 1937. Cultura Política, 5, 5.

Andrade, A. de (1941f). El concepto brasileño de municipio. Cultura Política, 9, 181. 